\title{
Workplace violence among emergency medical services workers in Riyadh, Saudi Arabia
}

\author{
Nesrin Alharthy*1, Mohammed Al Mutairi ${ }^{1}$, Abdullah Alsahli ${ }^{1}$, Ahmed Alshehri ${ }^{1}$, Abdullah Almatrafi $^{1}$, Ahmed Mahah ${ }^{2}$, \\ Abdulrahan Khalid Alswailem ${ }^{2}$, Winnie Philip ${ }^{3}$, Shoeb Qureshi ${ }^{3}$ \\ ${ }^{1}$ King Abdullah International Medical Research Center, King Saud bin Abdulaziz University for Health Sciences, college of \\ Applied Medical Science, Riyadh, Saudi Arabia \\ ${ }^{2}$ King Abdullah International Medical Research Center, Pediatric Emergency department, Riyadh, Saudi Arabia \\ ${ }^{3}$ Research Unit, College of Applied Medical Sciences, King Saud bin Abdulaziz University for Health Sciences, Riyadh, Saudi \\ Arabia
}

Received: February 14, 2017

DOI: $10.5430 /$ jha.v6n3p26
Accepted: March 31, 2017

Online Published: April 12, 2017

\begin{abstract}
Background: Globally, workplace violence toward health care providers is an area of concern. The impact of workplace violence on health care providers is significant.

Objectives: The study was conducted to evaluate the prevalence of workplace violence (physical and verbal) among emergency medical services (EMS) workers in Riyadh.

Methods: The study used a cross-sectional design that employed a self-administered confidential questionnaire, which was distributed to all emergency medical personnel. A well-structured and validated questionnaire on workplace violence was adopted from the World Health Organization for use in the study.

Results: A total of 370 EMS workers responded to the questionnaire. Workplace violence was experienced by $65 \%$ of the respondents. Verbal abuse (61\%) was the most common type of violence reported. The majority of the attackers were patients' relatives $(80 \%)$ followed by patients themselves $(51 \%)$. Respondents younger than 30 reported a higher percentage of violent acts than did older respondents $(p=.001$, Odds ratio $[\mathrm{OR}]=2.5,95 \%$ Confidence Interval $[\mathrm{CI}]=(1.6,3.9))$. Similarly, those who had fewer years of work experience ( $\leq 10$ years) reported a significantly higher percentage of violent incidents than those who had 10 or more years of experience $(p=.001, \mathrm{OR}=3.5,95 \% \mathrm{CI}=2.1,5.6)$. Only $10 \%$ of the victims reported the incident to a higher authority. Common reasons for not reporting the violent acts included feeling that it was useless (56\%) and that it was not important (52\%).

Discussion: The study demonstrates prevalent workplace violence among EMS workers, predominantly in the form of verbal abuse. The rate of workplace violence among EMS personnel is comparable with international figures. Less than half of EMS personnel exhibit knowledge regarding the process of violence reporting. However, workers tend not to report the incidents because they often believe that reporting is useless and/or not important.

Recommendation: With a high reported rate of workplace violence among EMS personnel, we recommend national preventive measures and encouragement to professionals to report violent events. We also recommend awareness programs for the identified vulnerable group.
\end{abstract}

Key Words: Workplace, Violence, Emergency medical services workers

*Correspondence: Nesrin Alharthy; Email: nesrin333@ @otmail.com; Address: King Abdullah International Medical Research Center, King Saud bin Abdulaziz University for Health Sciences, college of Applied Medical Science, Riyadh, Saudi Arabia. 


\section{INTRODUCTION}

Workplace violence is defined as violence or the threat of violence against workers that ranges from threats and verbal abuse to physical assault and homicide. Workplace violence is considered to be one of the leading causes of job-related death. ${ }^{[1]}$ The World Health Organization defines workplace violence as "incidents where staff are abused, threatened or assaulted in circumstances related to their work, including commuting to and from work, involving an explicit or implicit challenge to their safety, well-being or health". ${ }^{[2]}$ Globally, workplace violence toward health care providers is an area of concern. The impact of workplace violence on health care providers is significant. Studies have reported a wide range of psychosocial distress, burn-out and low perceptions of safety. ${ }^{[3,4]}$ Furthermore, occupational homicide is also reported as an outcome of workplace violence, including that occurring in health industries. ${ }^{[5,6]}$ The emergency department is the point of first contact with the hospital ward's health care workers, and workers in the emergency department were found to have a high risk of work place violence compared to non-emergency worker. ${ }^{[7]}$

The high vulnerability of the emergency hospital staff to violence was found to be related to several factors: low staffing levels, lack of staff training in recognizing and defusing potentially dangerous patients, lack of violence prevention programs, inadequate security, working in public places, and providing services, education and/or working with unstable or people with mental health problems. The risk of violence may be greater at certain times, such as the late hours of the night or early hours of the morning. ${ }^{[1,8,9]}$ Other triggering factors for violence directed against emergency department staff include patient pain and discomfort; the tension, stress, and anger of patients and family members; lack of privacy; and long waiting times for patients. ${ }^{[9]}$ Previous international studies support a high prevalence of workplace violence among emergency health care workers.

More than $70 \%$ of emergency health care workers report previous exposure to workplace violence. ${ }^{[1,8,10]}$ Studies reported high rates of psychological assaults versus physical assaults. The aggression of workplace violence may continue to increase, especially with the lack of preventive strategies and an effective reporting system. ${ }^{[11,12]}$

Prehospital care was identified as a predisposing factor for violence. A survey study that examined the rate of violence exposure among emergency medical services (EMS) workers reported that up to $60 \%$ of them encountered assault and $25 \%$ suffered physical injuries. ${ }^{[13]}$ Verbal abuse was the most prevalent form of violence against paramedics, with intimidation followed by physical abuse. Factors associated with

Published by Sciedu Press a high risk of violence included male gender, the patient's age, psychiatric illness, use of drugs, and time of the day. Majority of perpetrators were patients. ${ }^{[14-16]}$

Reports from Saudi Arabia examining workplace violence in hospital settings were similar to reports of international prevalence of violence against health care workers. Nurses working in psychiatric and emergency departments were the majority of the cases. Verbal violence was the most common form of violence. ${ }^{[1-19]}$ A major predictor for experiencing workplace violence was working in an emergency setting; however, there are no local studies that examine workplace violence in a prehospital setting. The aim of this study is to explore the rate of workplace violence toward ground ambulance paramedics and emergency medical teams.

\section{MeTHODS}

A cross-sectional study was used to survey EMS employees regarding occupational violence. The target population was the Saudi Red Crescent Authority (SRCA) and the EMS department of the Ministry of National Guard Health Affairs in Riyadh, the capital of Saudi Arabia. Male emergency medical personnel who consented to conduct a confidential workplace violence survey were included in the study. There were no female employees in EMS during the study period, so only male emergency medical technician (EMTs), paramedics and medics completed the survey. Sample size was calculated based on previous international reports, based on reported workplace violence prevalence to be $60 \%$ among EMS workers. The sample size was calculated as 370 EMS workers out of a population of approximately 10,000, 95\% confidence level, and confidence interval of 5.

A confidential self-reported questionnaire adopted from the World Health Organization was used to survey the participants about verbal and physical abuse in work place. Demographic data and details on workplace violence were collected. SPSS 22 (Statistical Package for the Social Sciences) was used for statistical analysis. A Pearson chi-square test was used to determine the association between exposure to work place violence and age and years of work experience with odds ratio and $95 \%$ CI. Frequencies and percentages were used for categorical variables. A $p$-value of less than $5 \%$ was found to be statistically significant.

\section{Results}

A total of 370 EMS workers participated in the study. The respondents were mostly young, with a mean age of $32.3 \pm 8$ years. Out of the $370,256(69.2 \%)$ were EMT workers, whereas $114(30.8 \%)$ were paramedics. 96 (25.9\%) of the respondents had more than 10 years of experience in the health care sector, while a majority $(274,74.1 \%)$ of 
them had $\leq 10$ years of work experience. A larger number of the respondents come from the East section of Riyadh $(104,28.2 \%)$. Table 1 shows the demographic features of the respondents.

Table 1. Demographic features of the respondents

\begin{tabular}{lll}
\hline \multirow{2}{*}{ Variable } & \multicolumn{2}{c}{ Details of respondents $(\mathbf{n}=\mathbf{3 7 0})$} \\
\cline { 2 - 3 } & Frequency & Percentage \\
\hline Age (years) & & \\
$\bullet<30$ & 187 & 50.5 \\
$\bullet \geq 30$ & 183 & 49.5 \\
Professional group & & \\
$\bullet$ Paramedic & 114 & 30.8 \\
$\bullet$ EMT & 256 & 69.2 \\
Work experience (years) & \\
$\bullet \leq 10$ & 274 & 74.1 \\
$\bullet>10$ & 96 & 25.9 \\
\hline
\end{tabular}

Among the 370 EMS workers, 239 (64.6\%) reported that they were victims of some kind of violence (verbal, physical or both) in the past 12 months. Out of 370 respondents, 230 $(62.2 \%)$ knew there are procedures for reporting violence in the workplace, and among those, 137 (59.6\%) knew how to use the procedures. $169(45.7 \%)$ respondents reported that they have been encouraged to report workplace violence. Figure 1 depicts the type of workplace violence. Verbal abuse $(145,61 \%)$ was the most common type of violence reported, followed by both physical and verbal abuse $(74$, $31 \%$ ). Physical abuse was identified in 20 (8.3\%) victims.

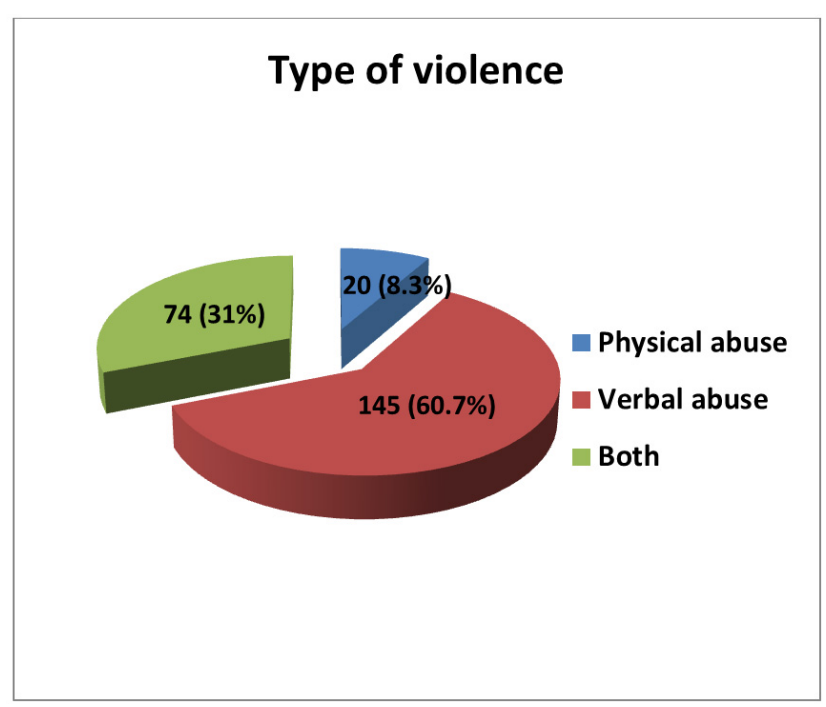

Figure 1. Pie diagram showing the type of workplace violence

One hundred forty-one (59\%) of the victims reported only one incidence of workplace violence. Thirty-three (14\%) of the victims encountered violent incidents more than five times. It was reported that the majority of assailants were relatives of patients $(191,79.9 \%)$, followed by patients themselves $(121,50.6 \%)$. The results showed that $230(96.2 \%)$ victims (physical abuse $=67,71.3 \%$, verbal abuse $=163$, $74.4 \%$ ) faced the violent incident outside the hospital institution. The majority $(111,46.4 \%)$ of the victims asked the assailants to stop hurting them, while 104 (43.5\%) took no action in preventing the violence. Out of the 94 respondents who experienced physical violence, 21 (22\%) tried to defend themselves. The characteristics of respondents who experienced workplace violence are described in Table 2.

The type of physical and verbal abuse is graphically represented in Figure 1. The study reported the most common type of physical abuse was pushing $(64,68 \%)$, followed by punching $(17,18 \%)$. Strangling and stabbing were observed in $2(2.1 \%)$ victims. $7(7.4 \%)$ were victims of slapping and arm-twisting. The types of verbal abuse reported were verbal insults toward the service $(75,34 \%)$, cursing the workers $(69,32 \%)$, verbal insult toward the institution $(40,18 \%)$, threatening physical harm $(31,14 \%)$ and threatening to kill $(7,3.2 \%)$ (see Figure 2).

With regard to violent incident reporting, only 24 (10\%) of respondents have reported the incidents. Ninety percent (215) of EMS workers have not reported the violent incidents to a higher authority. The reasons for not reporting the incident included the following: they felt it was useless (120, $55.8 \%)$, it was not important $(112,52.1 \%)$, they did not know to whom to report $(32,14.9 \%)$, they felt afraid of negative consequences $(17,7.9 \%)$, and they felt ashamed $(8,3.7 \%)$ (see Table 3).

A Pearson chi-square test was used to determine the association between exposure to workplace violence and the demographic features. The exposure to workplace violence was found to be significantly associated with workers who are $<30$ years of age $(p=.001)$ and with respondents with 10 or less years of work experience. The odds ratio indicated that there is 2.5 times more risk for the younger age group ( $<30$ years) to those aged $\geq 30$. Similarly, the risk of experiencing some sort of workplace violence was 3.5 times higher in those with fewer years $(\leq 10)$ of work experience than those with more years of work experience $(>10)$ (see Table 4).

\section{Discussion}

The study confirms the high prevalence of workplace violence among EMS workers. The most predominant form of violence was verbal abuse, which is consistent with the literature reports. ${ }^{[15,20]}$ The study also revealed other forms of workplace violence, such as physical abuse and a com- 
bination of verbal and physical abuse. A high prevalence of workplace violence was constantly reported, especially toward emergency personnel and nurses, for the last twenty years. ${ }^{[7,8,14,21]}$ International efforts to enforce interventions to prevent workplace violence occurred at multiple levels. The most important step is to encourage reporting. ${ }^{[1,2]}$ De-

Table 2. Characteristics of victims of workplace violence

\begin{tabular}{|c|c|c|c|c|c|c|}
\hline \multirow{3}{*}{ Characteristics } & \multicolumn{4}{|c|}{ Type of workplace violence $(n=239)$} & \multirow{2}{*}{\multicolumn{2}{|c|}{ Total $^{+}$}} \\
\hline & \multicolumn{2}{|c|}{ Physical violence $(n=94)$} & \multicolumn{2}{|c|}{ Verbal violence $(n=219)$} & & \\
\hline & No. & $\%$ & No. & $\%$ & No. & $\%$ \\
\hline \multicolumn{7}{|l|}{ Frequency of violence } \\
\hline - Once & 62 & 66.0 & 79 & 36.1 & 141 & 59 \\
\hline - 2-3 times & 25 & 26.6 & 79 & 36.1 & 104 & 43.5 \\
\hline - 4-5 times & 4 & 4.3 & 31 & 14.2 & 35 & 14.6 \\
\hline$\bullet>5$ times & 3 & 3.2 & 30 & 13.7 & 33 & 13.8 \\
\hline \multicolumn{7}{|l|}{ Attacker of violence (Assailants) ${ }^{*}$} \\
\hline - Patient & 25 & 27 & 96 & 43.8 & 121 & 50.6 \\
\hline - Relatives of patient & 60 & 64 & 131 & 59.8 & 191 & 79.9 \\
\hline - Staff member & 1 & 1.1 & 16 & 7.31 & 17 & 7.11 \\
\hline - Management/supervisor & 1 & 1.1 & 13 & 5.94 & 14 & 5.86 \\
\hline - External colleague & 4 & 4.3 & - & - & 4 & 1.67 \\
\hline - General public & 7 & 7.4 & 23 & 10.5 & 30 & 12.6 \\
\hline \multicolumn{7}{|l|}{ Place of violence } \\
\hline - Inside the institution & 24 & 25.5 & 44 & 20.1 & 68 & 28.5 \\
\hline - Outside the institution & 67 & 71.3 & 163 & 74.4 & 230 & 96.2 \\
\hline - Both & 3 & 3.2 & 12 & 5.5 & 15 & 6.3 \\
\hline \multicolumn{7}{|l|}{ Response to the violence $^{*}$} \\
\hline - Took no action & 16 & 17 & 88 & 40.2 & 104 & 43.5 \\
\hline - Tried to pretend it never happened & 8 & 8.5 & 40 & 18.3 & 48 & 20.1 \\
\hline - Told the person to stop & 39 & 41 & 72 & 32.9 & 111 & 46.4 \\
\hline - Tried to defend myself physically & 21 & 22 & - & - & 21 & 8.8 \\
\hline - Told friends/family & 4 & 4.3 & 22 & 10 & 26 & 10.9 \\
\hline - Told a colleague & 9 & 9.6 & 10 & 4.57 & 19 & 8.0 \\
\hline - Reported it & 7 & 7.4 & 17 & 7.76 & 24 & 10 \\
\hline
\end{tabular}

Note. ${ }^{*}$ Respondents were asked to choose more than one option; ${ }^{+}$The total will be more than 239 in view of the fact that some of the respondents are victims of both physical and verbal abuse

Regarding verbal abuse, $60 \%$ of the study participants were subjected to verbal abuse during their shift. Almost $70 \%$ of the participants were exposed to verbal threats between one and three times, and approximately $14 \%$ reported being exposed multiple times. Personal intimidation toward the EMS worker and service criticism were the most common forms of verbal abuse. Serious threats were also reported by the study participants, such as threats of physical harm and murder. Patient relatives and patients were the most commonly reported perpetrators; however, members of the general public were also reported as perpetrators in our study. The literature showed consistent findings with our study in spite the fact that our report found that up to $60 \%$ of respondents had prior knowledge of reporting procedures, only a few $(10 \%)$ actually reported the violence. More than $50 \%$ perceive that reporting violence is useless and/or not important. 
majority of participants, were mainly pushing and punching. $2 \%$ reported assault by weapon; assault with a weapon was also described in the literature evaluating workplace violence among EMS workers. ${ }^{[3,14,22]}$ Patients' relatives were responsible for the majority of the attacks, accounting for more attacks than the patients identified as attackers in our report. Among participants who were physically harmed, only $7 \%$ reported the event. Most likely, those who reported the attack were subjected to serious threats and/or actual harm.

Regarding verbal abuse, $60 \%$ of the study participants were subjected to verbal abuse during their shift. Almost $70 \%$ of the participants were exposed to verbal threats between one and three times, and approximately $14 \%$ reported being exposed multiple times. Personal intimidation toward the EMS worker and service criticism were the most common forms of verbal abuse. Serious threats were also reported by the study participants, such as threats of physical harm and murder. Patient relatives and patients were the most commonly reported perpetrators; however, members of the general public were also reported as perpetrators in our study. The literature showed consistent findings with our study in reporting verbal abuse as the most common form; however, the prevalence varied across reports from $20 \%$ up to $90 \%$ of participants. ${ }^{[14-16]}$ Most studies indicated similar findings on the reported perpetrators and EMS service criticism. ${ }^{[14-16]}$ In our study, we reported that members of the general public were involved in verbal abuse, which indicated a trend, especially in the Middle East. ${ }^{[22]}$

Table 3. Reporting of workplace violence by the victims and reasons for those who have not reported the incidence

\begin{tabular}{ll}
\hline \multirow{2}{*}{ Features } & Details of victims \\
\cline { 2 - 2 } & No. $(\%)$ \\
\hline Reported the incidence $(\mathrm{n}=239)$ & $24(10 \%)$ \\
- Yes & $215(90 \%)$ \\
- No & \\
Reasons for not reporting ${ }^{*}(\mathrm{n}=215)$ & $112(52.1 \%)$ \\
- It was not important & $8(3.7 \%)$ \\
- Felt ashamed & $17(7.9 \%)$ \\
- Afraid of negative consequences & $32(14.9 \%)$ \\
- Don't know to whom to report & $120(55.8 \%)$ \\
- Useless & $10(4.7 \%)$ \\
- Other reasons & \\
\hline
\end{tabular}

Note. ${ }^{*}$ Victims were asked to choose more than one option
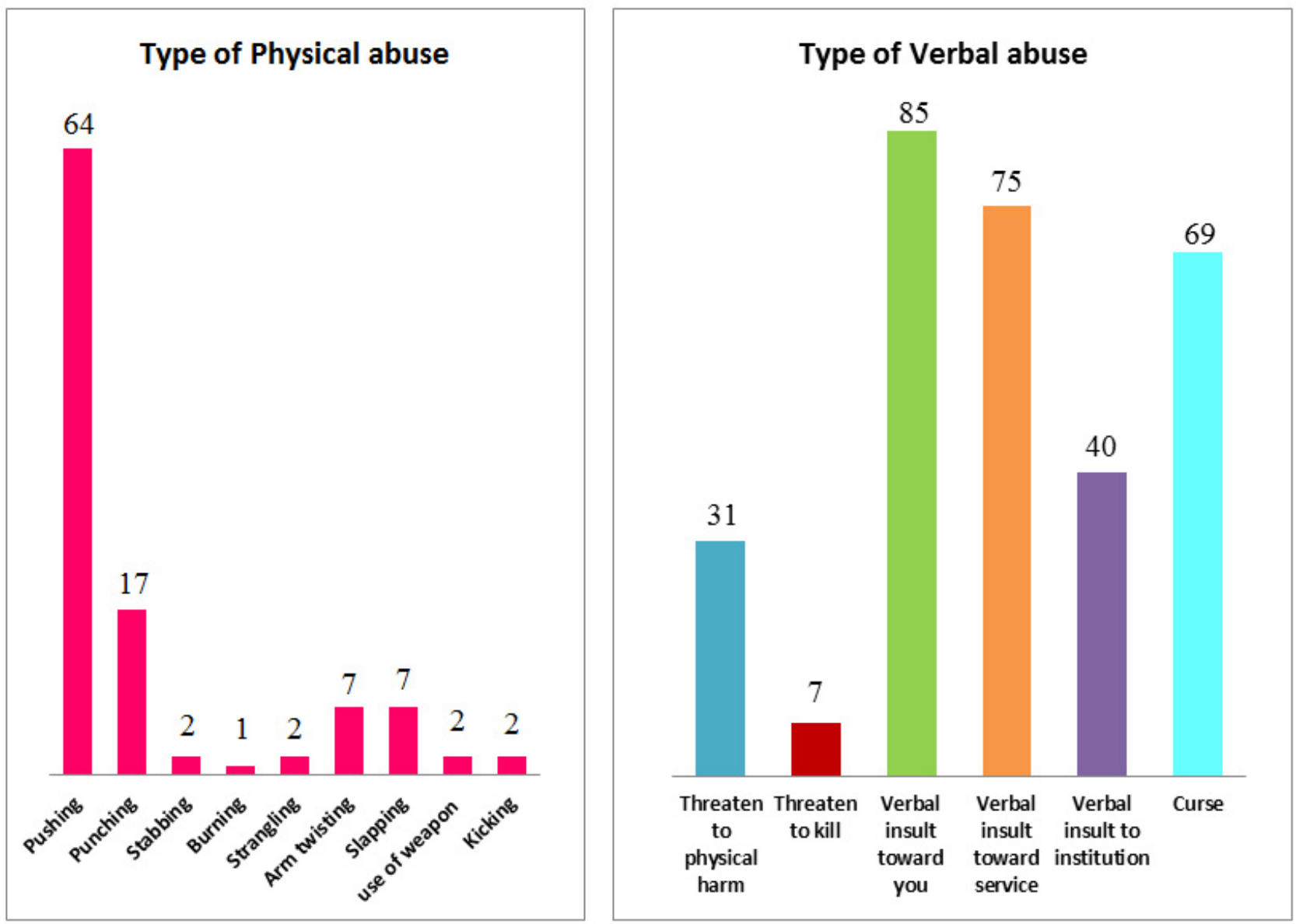

Figure 2. Bar diagram showing the frequency of victims with Physical $(n=94)$ and Verbal abuse $(n=219)$ 
Table 4. Association of respondents characteristics and exposure to workplace violence with Chi square $\left(\chi^{2}\right), p$-value, Odds Ratio (OR) and 95\% Confidence Interval (CI)

\begin{tabular}{|c|c|c|c|c|c|c|c|c|c|c|}
\hline \multirow{4}{*}{ Characteristics } & \multicolumn{10}{|c|}{ Details of respondents } \\
\hline & \multicolumn{6}{|c|}{ Exposure to workplace violence in the past 1 year } & \multirow{3}{*}{$\chi^{2}$} & \multirow{3}{*}{$p$-value } & \multirow{3}{*}{ OR } & \multirow{3}{*}{$95 \% \mathrm{CI}$} \\
\hline & \multicolumn{2}{|c|}{ Yes $(n=239)$} & \multicolumn{2}{|c|}{ No $(\mathbf{n}=131)$} & \multicolumn{2}{|c|}{ Total $(\mathbf{n}=370)$} & & & & \\
\hline & No. & $\%$ & No. & $\%$ & No. & $\%$ & & & & \\
\hline \multicolumn{11}{|l|}{ Age (years) } \\
\hline$\bullet<30$ & 140 & 74.9 & 47 & 25.1 & 187 & 100 & 17.44 & $.001^{*}$ & 2.5 & $(1.6,3.9)$ \\
\hline$\bullet \geq 30$ & 99 & 54.1 & 84 & 45.9 & 183 & 100 & & & & \\
\hline \multicolumn{11}{|c|}{ Work experience (years) } \\
\hline$\bullet \leq 10$ & 198 & 72.3 & 76 & 27.7 & 274 & 100 & 27.15 & $.001^{*}$ & 3.5 & $(2.1,5.6)$ \\
\hline$\bullet>10$ & 41 & 42.7 & 55 & 57.3 & 96 & 100 & & & & \\
\hline \multicolumn{11}{|c|}{ Professional group } \\
\hline - Paramedic & 69 & 60.5 & 45 & 39.5 & 114 & 100 & 1.19 & .275 & - & - \\
\hline - EMT & 170 & 66.4 & 86 & 33.6 & 256 & 100 & & & & \\
\hline
\end{tabular}

Note. ${ }^{*}$ Significant at $5 \%$

Regarding verbal abuse, $60 \%$ of the study participants were subjected to verbal abuse during their shift. Almost 70\% of the participants were exposed to verbal threats between one and three times, and approximately $14 \%$ reported being exposed multiple times. Personal intimidation toward the EMS worker and service criticism were the most common forms of verbal abuse. Serious threats were also reported by the study participants, such as threats of physical harm and murder. Patient relatives and patients were the most commonly reported perpetrators; however, members of the general public were also reported as perpetrators in our study. The literature showed consistent findings with our study in reporting verbal abuse as the most common form; however, the prevalence varied across reports from $20 \%$ up to $90 \%$ of participants. ${ }^{[14-16]}$ Most studies indicated similar findings on the reported perpetrators and EMS service criticism. ${ }^{[14-16]}$ In our study, we reported that members of the general public were involved in verbal abuse, which indicated a trend, especially in the Middle East. ${ }^{[22]}$

EMS workers in our report were also subjected to combined verbal and physical abuse in $30 \%$ of cases. Physical abuse was reported in $8 \%$ of incidents. Unlike verbal abuse, the majority of our participants were exposed to 1 event of physical abuse. Incidents of physical harm, as reported by the majority of participants, were mainly pushing and punching. $2 \%$ reported assault by weapon; assault with a weapon was also described in the literature evaluating workplace violence among EMS workers. ${ }^{[3,14,22]}$ Patients' relatives were responsible for the majority of the attacks, accounting for more attacks than the patients identified as attackers in our report. Among participants who were physically harmed, only $7 \%$ reported the event. Most likely, those who reported the attack were subjected to serious threats and/or actual harm.
Working in a prehospital setting with acutely ill patients exposes the EMS worker to increased risk of workplace violence. This was reflected by the majority of EMS workers, who were victims of violence outside the hospital institution. Studies have documented high risk for workplace violence among female paramedics and EMS workers with fewer years of experience ${ }^{[15,20]}$ Emergency medical technicians younger than 30 years of age with less than ten years of experience were associated with high risk to exposure to workplace violence in our study. Timing of the shift and catchment area were not recognized as predisposing factors for workplace violence in our report.

\section{Conclusions}

Our study documented the existence of workplace violence among EMS workers in Riyadh. The reported prevalence is consistent with international figures, highlighting the significantly high prevalence of workplace violence among paramedics and EMTs. A collaborative effort is mandated to implement effective reporting and national preventive strategies. Education and support groups should be provided, especially to those identified as at high risk for workplace violence.

Limitations This is a retrospective survey that is subject to information and recall bias. The information was obtained based on EMS workers' reporting of events, which may not reflect the reality compared to the number of formal reports of violence. The study was conducted in Riyadh, which limits the generalizability of the findings to other regions of Saudi Arabia.

\section{ACKNOWLEDGEMENTS}

We would like to thank the Saudi Red Crescent Authority 
(SRCA) and the Emergency Medical Services department of the Ministry of National Guard Health Affairs, who allowed their EMS workers to contribute to the study.

\section{CONFLiCTS OF InTEREST Disclosure}

The authors declare they have no conflict of interest.

\section{REFERENCES}

[1] OSHA fact sheet, Workplace violence, U.S. Department of Labor Occupational Safety \& Health Administration. T: 800-321-OSHA (6742) TTY. Available from: https://www.osha.gov/OshDoc/data_General_Facts /factsheet-workplace-violence.pdf

[2] ILO/ICN/WHO/PSI Joint Programme on Workplace Violence in the Health Sector. Framework guidelines for addressing workplace violence in the health sector / Joint Programme on Workplace Violence in the Health Sector. Accessed 7 April 2015. Available from: http://www . who.int/iris/handle/10665/42617

[3] Kansagra SM, Rao SR, Sullivan AF, et al. A survey of workplace violence across 65 U.S. emergency departments. Acad Emerg Med. 2008 Dec; 15(12): 1268-74. PMid: 18976337. https://doi.org/ $10.1111 / \mathrm{j} .1553-2712.2008 .00282 . \mathrm{x}$

[4] Howard PK, Gilboy N. Workplace Violence. Adv Emerg Nurs J. 2009 Apr-Jun; 23(2): 94-100. PMid: 20118858. https ://doi .org/10 .1097/TME. 0b013e3181a34a14

[5] Menendez CC, Konda S, Hendricks S, et al. Disparities in workrelated homicide rates in selected retail industries in the United States, 2003-2008. Journal of Safety Research. 2013 Feb; 44(11) 25-9. PMid: 23398701. https://doi.org/10.1016/j.jsr.20 12.12 .002

[6] Jenkins EL. Workplace homicide: industries and occupations at high risk. Occupational medicine (Philadelphia, Pa). 1996 Apr-Jun; 11(2) 219-25. PMid: 8936251

[7] Esmaeilpour M, Salsali M, Ahmadi F. Workplace violence against Iranian nurses working in emergency departments. International nursing review. 2011 Mar; 58(1): 130-7. PMid: 21281305. https //doi.org/10.1111/j.1466-7657.2010.00834.x

[8] Gacki-Smith J, Juarez AM, Boyett L, et al. Violence against nurses working in US emergency departments. The Journal of Nursing Administration. 2009 Jul-Aug; 39(7-8): 340-9. PMid: 19641432. https://doi.org/10.1097/NNA.0b013e3181ae97db

[9] Ayranci U. Violence toward health care workers in emergency departments in west Turkey. The Journal of Emergency Medicine. 2005 Apr; 28(3): 361-5. PMid: 15769589. https://doi.org/10.101 $6 / j \cdot j$ emermed.2004.11.018

[10] Gillespie GL, Gates DM, Miller M, et al. Workplace violence in healthcare settings: risk factors and protective strategies. Rehabilitation Nursing : The Official Journal of the Association of Rehabilitation Nurses. 2010 Sep-Oct; 35(5): 177-84. PMid: 20836482. https://doi.org/10.1002/j.2048-7940.2010.tb00045.x

[11] Baydin A, Erenler AK. Workplace violence in emergency department and its effects on emergency staff. International Journal of
Emergency Mental Health. 2014; 16(2): 288-90. PMid: 25585480. https://doi.org/10.4172/1522-4821.1000112

[12] Kowalenko T, Cunningham R, Sachs CJ, et al. Workplace violence in emergency medicine: current knowledge and future directions. The Journal of Emergency Medicine. 2012 Sep; 43(3): 523-31. PMid: 22633755. https://doi.org/10.1016/j.jemermed.2012.02 .056

[13] Corbett SW, Grange JT, Thomas TL. Exposure of prehospital care providers to violence. Prehospital emergency care : official journal of the National Association of EMS Physicians and the National Association of State EMS Directors. 1998 Apr-Jun; 2(2): 127-31.

[14] Grange JT, Corbett SW. Violence against emergency medical services personnel. Prehospital emergency care : official journal of the National Association of EMS Physicians and the National Association of State EMS Directors. 2002 Apr-Jun; 6(2): 186-90

[15] Boyle M, Koritsas S, Coles J, et al. A pilot study of workplace violence towards paramedics. Emergency Medicine Journal: EMJ. 2007 Nov; 24(11): 760-3. PMid: 17954828. https ://doi .org/10.113 $6 / \mathrm{emj} \cdot 2007.046789$

[16] Bigham BL, Jensen JL, Tavares W, et al. Paramedic self-reported exposure to violence in the emergency medical services (EMS) workplace: a mixed-methods cross-sectional survey. Prehospital emergency care : official journal of the National Association of EMS Physicians and the National Association of State EMS Directors. 2014 Oct-Dec; 18(4): 489-94.

[17] El-Gilany AH, El-Wehady A, Amr M. Violence against primary health care workers in Al-Hassa, Saudi Arabia. Journal of Interpersonal Violence. 2010 Apr; 25(4): 716-34. PMid: 19494243. https://doi.org/10.1177/0886260509334395

[18] Algwaiz WM, Alghanim SA. Violence exposure among health care professionals in Saudi public hospitals. A preliminary investigation. Saudi Medical Journal. 2012 Jan; 33(1): 76-82. PMid: 22273653.

[19] Mohamed AG. Work-related assaults on nursing staff in riyadh, saudi arabia. Journal of Family \& Community Medicine. 2002 Sep; 9(3): 51-6. PMid: 23008680

[20] Boyle M, McKenna L. Paramedic and midwifery student exposure to workplace violence during clinical placements in Australia - A pilot study. Int J Med Educ. 2016 Dec 11; 7: 393-399. https: //doi.org/10.5116/ijme.582e.ac04

[21] Tintinalli JE, McCoy M. Violent patients and the prehospital provider. Ann Emerg Med. 1993 Aug; 22(8): 1276-9. https ://doi .org/10 .1016/S0196-0644(05) 80106-4

[22] Gülen B, Serinken M, Hatipoğlu C, et al. Work-related injuries sustained by emergency medical technicians and paramedics in Turkey. Ulus Travma Acil Cerrahi Derg. 2016 Mar; 22(2): 145-9. https://doi.org/10.5505/tjtes.2015.94224 